\title{
Physical Education Method: Effects on Physical Fitness and Competency of the Students
}

\author{
${ }^{1}$ Mohammad Nikravan, ${ }^{2}$ Ali Mohammad Safania*, ${ }^{3}$ Ali Zareii \\ ${ }^{1}$ Department of Physical Education, Borujerd Branch, Islamic Azad University, Borujerd, Iran. \\ ${ }^{2}$ Department of Physical Education, Science and Research Branch, Islamic Azad University, Tehran, Iran. \\ ${ }^{3}$ Department of Sport Management, Faculty of Physical Education and Sport Science, Central Tehran \\ Branch, Islamic Azad University, Tehran, Iran
}

Submitted 25 September 2018; Accepted in final form 14 December 2018.

\begin{abstract}
Background. Due to the fact that the current methods used in Iran are old-fashioned and their theoretical foundations are based on authority of teachers, there is a necessity to adopt and enjoy new and creative methods which are depended upon peer learning of students who are actively involved in working with each other. These features are the cornerstone of sport education (SE) method whose procedure is to teach students to be self-dependent and participate in all parts of the class unlike traditional methods of sport education. Objectives. The current study aimed at comparing the effects of traditional method (current methods in Iranian schools) with sport education on physical fitness and competency. Methods. The current semi-experimental study focused on the effects of two methods of sport education and traditional method. The statistical population included the junior students of 2nd grade in Sama School in Boroujerd of which two 18-subject groups were selected; the first group was trained based on the sport education method and the 2nd group based on traditional method in volleyball. Each group separately attended sport education and traditional method classes. In the sport education group, the students attended 12 sessions according to the procedure of sport education, formerly introduced by Siedentop; in the traditional method group, the students also attended 12 sessions, based on the running method in volleyball. For the sport education group, before starting the season, the participants were asked to take the physical fitness and competency pre-tests. Likewise, the traditional method group took the same tests before starting the program. Then, the participants in each group were trained in accordance with the structure, procedure, and lesson plan of the running method. After completion of training, the participants were asked to take the posttests of physical fitness and competency. Then, the data from pre- and posttests were gathered and compared using ANCOVA and analyzed with SPSS. Results. Intergroup comparisons showed a significant difference between the two groups in physical fitness (except for jumping index); intragroup comparison also showed a significant difference between pre- and posttest results in each group in terms of competency. Therefore, the sport education had a significant priority to the traditional method. Conclusion. Our results suggest that instead of using common and traditional teaching methods for physical education in schools, colleges and universities, it is better to use modern methods, especially sports education.
\end{abstract}

KEY WORDS: Students, Physical Fitness, Competency, Physical Education, Sports Education

\section{INTRODUCTION}

The notion of sport education was introduced in 1994 with the publication of the book Sport
Education: Quality PE through Positive Sport Experiences. The use of the term sports in this

*. Corresponding Author:

Ali Mohammad Safania, Professor

E-mail: a.m.safania@gmail.com 
model is more comprehensive than that usually used as part of a sports program in the United States. It is affected unequivocally by the sport for all advances in Europe, bolstered by the United Nations Educational, Scientific, and Cultural Organization (UNESCO). The term sport in the European setting alludes to any type of moderate to vivacious physical movement, including strolling, biking, trekking, fitness exercises; but the numerous exercises known as games in the United States. Sport education seasons are developed for most focused games as well as different types of move, orienteering, rope bouncing, and weight training (1).

Sport education is a pedagogical model in light of the idea that slight mixed-ability learning teams cooperate in ways such that all colleagues benefit from advantage and experience. Sport education gives understudies sufficient time to improve their abilities and figure out how to satisfy the group parts for a fruitful sport education season. Therefore, sport education seasons are constantly more than run of the mill physical training units, and understudies have more to learn than just tactics and strategies for the regular rivalries to be fruitful (1).

Additionally, one could undoubtedly say that sport education is an educational program and direction model intended to furnish understudies with bona fide encounters that are careful and agreeable and that add to their yearning to end up and stay physically dynamic for the duration of their lives. The sport education model was expanded in the mid-1990s. The components of the model that recognize it from conventional ways to deal with instructing physical training are as the following based on Siedentop's idea:

Units, or seasons, are longer than typical physical education units. Elementary seasons typically last from 10 to 12 sessions, whereas middle and high school seasons typically last from 18 to 20 sessions.

Students are organized into mixed-ability teams at the start of a season and maintain their affiliation throughout the season. Every effort is made to ensure that the teams are homogenous as much as possible in terms of the activity for the season.

Students on each team learn multiple roles. The exact roles for each season change depending on the activity. In addition, to each student being a player, typical roles for sport seasons are coach, equipment manager, referee, scorekeeper, and statistician. Other roles would be used for other activities.

Activities are typically modified so that all students can learn and be successful. Games are often small-sided compared with the parent form of the game (e g, $3 \mathrm{v} 3$ soccer, $2 \mathrm{v} 2$ volleyball).

Teams are gradually introduced to the activity for the season, focusing on the techniques and tactics needed to perform adequately in the activity.

The season typically consists of a series of competitions; for instance, a soccer season might start with 1v1 competitions, then continue with $2 \mathrm{v} 2$, and finish with a $4 \mathrm{v} 4$ final competition. Dance or weightlifting seasons would start with easier dances and lifts and move toward more difficult dances and lifts.

The most typical organizational format is three mixed-ability teams. In competitions, two teams compete, while the third acts as a duty team (e g, referees, scorekeepers, judges).

In sport education seasons, records of performances are kept and made public throughout the season, not only to determine seasonal standings and championships, but also to inform students of their own development within the season (e g, reduced times in a $46 \mathrm{~m}$ dash during a track and field season or points scored and rebounds during a 3v3 basketball season).

Seasonal champions are typically determined by a point system that can include points for items such as daily teamwork, fair play, duty-team performance, and tournament performance.

The entire season is designed to be festive, culminating in the final event, which celebrates the season with awards for competition standings, student performance roles such as duty-team performances, and fair play points (1).

A noteworthy objective of sport education is for understudies to be a main part in an action that is altogether charming and gives trust and confidence to perform in the action all through the span of the season; along these lines inspiring them to keep on learning, and enhance in this manner expanding the chances that they will look for to take an interest in their optional time. It is believed that this objective is more averse to be accomplished in the ordinary organization for school physical instruction with short units in which the guardian types of diversions are utilized for rivalries (1).

In the developed countries, several studies are conducted on sport education, which highlight the 
importance of performing such a study in a developing country like Iran. In 2018, an original article entitled 'Exploring Pre-service Teachers' Experience of Sport Education as an Approach to Transition Pedagogy" by Amanda Mooney et al., was published. The study explored experiences of pre-service health and physical education (HPE) teachers in a sport education unit that was strategically designed and placed to support their transition from a primary teacher in health and physical education and to consider how such experiences shaped perceptions of belonging and pedagogical practice. The research highlighted the importance of transition pedagogies embedded within curricula targeting HPE teachers to contribute to a sense of belonging and connectedness. Furthermore, the findings demonstrated specific pedagogical features for these participants that were integral to inclusive, and engaging the positive first-year experiences and the questions raised about practices that potentially reinforced marginality through various workings of power in HPE teacher preparation programs (2).

In 2017, another study entitled "Developing Effective Student Coaches in Sport Education" was performed by Tristan Wallhead et al. The authors referred to the fact that the sport education model adopts a student-centered instructional approach where students are asked to take on roles and responsibilities other than that of players. One critical role to develop student knowledge and performance is that of the student coach. They introduced some potential strategies that can be used by the teachers to more effectively facilitate training of student coaches in sport education. They included: (i) selecting student coaches, (ii) delineating coach expectations, (iii) providing guided-practice on basic pedagogical skills, (iv) developing student coach independence with problem-solving capacities, and (v) developing accountability for coaching performance. Coaching seminars can also be introduced as a method to increasing coaching effectiveness (3).

Another study entitled: "Sport Education: A Model for Engaging Teachers and Students" was performed by Peter and Tristan Wallhead. The essential features of the sport education model were outlined in their study, as told by a teacher to an inquiring principal. The key purpose of the study was to identify the key aspects upon which sport education is based, and also to show how it is different from simply taking interschool or community sport directly into physical education. Their paper finishes with a brief discussion of the notion of the competent, literate, and enthusiastic player-the fundamental goal of sport education (4).

The same authors in another study entitled "Designing a Sport Education Season: Key Factors to Consider" took a teacher through the decision tree and found it helpful to design seasons of sport education. Starting with curricular factors such as the selection of the sport, and the length of a season, move was made to more pedagogical factors such as the allocation of students to teams, the development of the roles, as well as the progression of the content. Finally, ways were examined in which a season of sport education can be made, particularly festive through the creation of various culminating events (5).

Another study was "Pursuing Physical Education Outcomes through Sport Education" performed by Shane Pill and John Williams. They stated that teaching sport and sport-related games are integral components of Australian physical education programs. The question confronting teachers of physical education is not whether sport is a component of physical education, but why particular pedagogical models should guide the construction of curricula and the enactment of teaching. It was argued that models such as the sport education model facilitate a more authentic, educationally remarkable and equitable learning of sport within physical education. To support this argument, it is explained how the sport education model delivers the tenets of teaching for effective learning (TFEL) and how it provides key ideas and capabilities of the Australian HPE curriculum. It was concluded by suggesting sport education as a curriculum connector for authentic middle schooling pedagogy (6).

Tristan Wallhead published another article named "Developing effective student coaches in Sport Education" in 2017. The Sport Education Model adopts a student-centered instructional approach where students are asked to take on roles and responsibilities other than that of players. One critical role to develop student knowledge and performance is that of the student coach. This article introduces some potential strategies that can be used by the teachers to facilitate training more effective student coaches in Sport Education. They include: (i) selecting 
student coaches, (ii) delineating coach expectations, (iii) providing guided-practice on basic pedagogical skills, (iv) developing student coach independence and problem-solving capacities, and (v) developing accountability for coaching performance. The use of coaches' seminars is also introduced as a method of increasing coaching effectiveness (7).

Cláudio Farias in a study entitled: "Promoting Equity and Social Responsibility within Sport Education" stated that sport education is highly favorable to the development of positive responsibility and more equitable and inclusive learning contexts. He offered an integrated evidence-based analysis of the development of positive responsibility, inclusion, and equitable learning environments within sport education. The study also highlighted the sociocultural and structural constraints to the development of such goals, and pointed out four practical pedagogical interventions for the proactive development of inclusion, equity, and positive responsibility in sport education. These interventions were as follows: (i) developing positive and responsible membership; (ii) developing positive and responsible peer leadership; (iii) designing developmentally appropriate and cooperationfacilitative learning activities; and (iv) reshaping the meaning of winning for legitimating different levels of participation and membership (8).

Todd Layne in article study entitled "Sport Education in the Primary Grades" referred to the fact that while a profusion of research shows the effectiveness of sport education, some still question the appropriateness of the model within the early primary years. In his study, suggestions are provided for readers to use sport education with the early primary years. Specifically, these relate to the issue of choosing an appropriate class, an appropriate motor skill, and the way of managing team and duty roles. In addition, implementing the steps can help teachers to maximize the benefits of the model in dealing with younger students (9).

"Scaffolding Student-Coach Instructional Leadership Toward Student-centered Peer Interactions: A Yearlong Action-research Intervention in Sport Education" by Cláudio Farias et al., was the first in sport education to provide a yearlong, in-depth examination of the scaffolding processes used by a teacher during student participation in four consecutive seasons. Given the peer teaching format of the learning activities and curriculum ownership allocated to students, a focus was placed on the preparation of the students in the role of team coaching to conduct instructions in student-centered interactions (active engagement of teammates in problem-solving, discovery, and the construction of knowledge). Findings showed that the scaffolding of the student-coach instructional leadership was a non-linear process contingently adjusted in reference to aspects such as studentcoache progress in the mastery of instructional processes, the complexity of the domain-specific content, and the nature of the sports. As the student-coach developed knowledge of content and instruction, they became increasingly selfassisted in the conduct of the learning activities (10).

Another study entitled "Future Research Directions for Sport Education: Toward an Entrepreneurial Learning Approach" by Vanessa Ratten introduced an entrepreneurial learning approach to the study of sport education in order to inform future research directions. Sport education needs to focus on how it can overcome existing barriers to bring a more interdisciplinary approach. The current study used entrepreneurship education theory to explore the changes required in sport education provision to create a more relevant and conducive teaching environment. The findings of the study suggest that by bringing sport students into contact with entrepreneurship education, it aids in the development of improved employability and social skills (11).

Vanessa Ratten also published "Sport Education: Fit for a Purpose", referring to the fact that sport is a major social phenomenon and transcends ethnic and geographical boundaries. There is an increase in the number of research focusing on sport education as it enables instructions involving experiential and real-life learning methods. This is due to limited research on linking sport education to other academic disciplines such as entrepreneurship education. The main feature of sport education is to incorporate the cultural and societal context endemic into a sport context. This is important to appreciate different ways that sport is perceived in the community and the challenges of sport teaching. Her study reviewed and suggested guides for sport education research (12).

Another study entitled: "Mediating Peer Teaching for Learning Games: An Action 
Research Intervention Across Three Consecutive Sport Education Seasons" by Cláudio Farias et al., provided an integrated analysis of a teacher peer-teaching mediation strategies, the studentcoaches instruction, and the students gameplay development across three consecutive seasons of sport education. Aspects such as the study of predominant configurations of players' gameplay and similar tactical principles across games within the same category prevented a setback in the complexity of the learning content addressed at the beginning of each season. Players also showed an increasing ability to adapt gameplay to game conditions (13).

According to the importance of sport education, the research therefore aimed at (1) comparing the influence of traditional and sport education methods on the physical fitness of the participants and (2) comparing the influence of traditional and sport education methods on the competency of the participants.

Traditional Method. It is a method in which each issue is taught separately. It is also considered as a method used repeatedly by most of the schools during the history of teaching, and today is also considered as one the most wellknown methods. In this method, the issue or skill is explained and executively taught by the teacher. Teacher also modifies any possible fault. Among the features of this method, a specific amount of time, the ability to adapt to low equipment, not dependent on the ability of the students, and the minute details are noteworthy $(14,15)$.

Sport Education. Sports education is a curriculum developed in physical education programs in elementary, middle, and high school levels. This method is to provide a more authentic sports experience, which is more enjoyable for children and young people and beyond what is usually seen in physical education classes. This method was introduced by Daryl Seidentop in 1984 and since then gained a national and international adaptation and success. In this model, the students are considered as a team in a season that is longer than regular seasons. In this season, an active role in the direction of the team as captain, coach, official records, publicist, and members of the sports council is given to each student. The concept of the team is also applied through team uniforms, team name, and fans as a significant development tool for learning the skills that are being played.
The goal of sport education is to educate students to be players in the fullest sense and to help them to be developed as competent, literate, and enthusiastic sportspersons. Girls and boys well experienced in a sport education program from forth to 12th grades should be reasonably well skilled in a variety of sport, dance, and fitness activities; more likely to become and stay involved in physical activities during discretionary time; able to differentiate between good and bad sport practices whether in youth, school, or community sports; and more likely to be engaged with local sport organizations as adults to ensure that child and youth sport programs are designed to enhance the well-being of those participating. Thus, the goals for sport education are to educate players in the fullest sense and help them to be developed as competent, literate, and enthusiastic sportspersons (1).

Physical Fitness. Physical fitness is the body's ability to work effectively and efficiently. It is in relation with a person's ability to work efficiently, enjoy leisure, and be healthy and powerful in status during life time (16). Physical fitness is the ability to live a balanced and complete inventory life, or it can be considered as doing daily tasks without exhaustion and high energy consumption. In addition to the physical health, a person should have good attributes such as human behavior, which is based on moral principles. Physical education programs seriously consider physical fitness and try to improve physical fitness and overall wellbeing.

Competency. A competent sportsperson develops sufficient skill to participate in games and activities satisfactorily, understands and can execute strategies appropriately to the complexity of the activity, and is a knowledgeable game player. Through sport education, students learn to be comfortable and competent in performing complex sport, dance, and fitness activities. They grow their abilities and confidence by gradually being familiar with sport techniques and tactics and having ample time to be developed through practices and competitions (17). Psychologists define competency as attributes or skills that lead to better performance. In selection of the most competent persons, abilities, behavioral characteristics, beliefs, personality traits, attitudes, and skills should be considered.

There are a few studies on sport education and according to the authors, the following ones are 
the best examples: Julie S. Stoekly in a study entitled: "Sport Education and the Traditional Unit Approach: A Comparison of Student Activity Levels" introduced sport education as a curriculum model in physical education that promotes student responsibility and positive social skills. Healthy People Organization recommended students to spend at least $50 \%$ of the studying time on moderate to vigorous physical activities. This study was designed to compare the level of student activity between the traditional unit approach and the sport education curriculum. The procedure dealt with the (SOFIT: System for Observing Fitness Instruction Time) coding system and total number of steps obtained by students using pedometers used as measures of activity to compare models. An AB treatment design was utilized to rotate curriculum models across two classes. The findings indicated that class A spent $64.45 \%$ of lesson time on sport education in average, and group B spent in average $60.23 \%$ of lesson time on sport education. According to data collected from pedometers and SOFIT, class A had higher activity levels in sport education than in the traditional unit approach, and class B had higher activity levels in the traditional unit approach than in sport education. Consequently, in this study, the sport education model was an effective approach to meet the recommendations of Healthy People Organization, suggesting that students spend at least $50 \%$ of lesson time on moderate to vigorous physical activities. Although class B had lower activity levels in the sport education class, the class still averaged higher than $50 \%$ of lesson time on moderate to vigorous activities.

In another research by Tom B.J. Browne et al., entitled: "A Comparison of Rugby Seasons Presented in Traditional and Sport Education Formats", the impact of two instructional approaches in teaching rugby was studied on students' learning, enjoyment, and affection. Fifty-three boys (aged 12-13) from a large metropolitan private school for boys in Eastern Australia participated in either a 20 unit of rugby union taught using a skill-drill-game approach (n $=26$ ), or a 20 season lesson following the sport education model $(n=27)$. The results of their study indicated that both groups made significant improvements in their knowledge of the game as well as their skills. In addition, the students in sport education showed significant achievements in perceived learning and also reported that they developed a better understanding of the game. The differences between the two conditions can be explained by the increased affiliation and feelings of belonging, and membership in the sport education arena.

Another research by Tristan L. Wallhead and Nikos Ntoumanis entitled: "The Effects of a Sport Education Intervention on Students' Motivational Responses in Physical Education" dealt with the influence of a sport education intervention on students' motivational responses in a high school physical education setting. Two intact groups were assigned to curricular interventions: the sport education group $(n=25)$, which received eight 60-minute education sessions and the control group $(n=26)$, which received a traditional teaching approach to sport-based activity. Pre- and post-intervention measures of student enjoyment, perceived effort, perceived competence, goal orientations, perceived motivational climate, and perceived autonomy were obtained for both groups (18-20). Repeated measures ANOVA showed significant increases in student enjoyment and perceived effort in the sport education group only. Hierarchical regression analyses revealed that increases in task-involving climate and perceived autonomy explained a significant amount of unique variance in the intervention enjoyment, perceived effort, and perceived competence responses of the sport education group. The results suggested that the sport education curriculum may increase perceptions of a task-involving climate and autonomy, and accordingly, enhance the motivation of high school students toward physical education (21).

\section{MATERIALS AND METHODS}

Research Design. The research was practical based on its aims and semi-experimental based on its nature. Two groups of students were chosen to participate in the research; one group was trained based on traditional approach and the other one based on sport education. Each group participated in classes held based on the structures of each method in a way that in the sport education group, the students attended 12 sessions based on the procedure of sport education, and the traditional approach group, received traditional method, and the students attended 12 sessions as well, but based on the procedure and structure of traditional method in volleyball. For the sport education 
group, before starting the season, the participants were asked to take the pre-tests including physical fitness and competency. Likewise, for the group trained based on traditional method, before starting the session, the participants were asked to take the same pre-tests. Then, the participants in each group were trained in accordance with the structure, procedure, and lesson plan of the running model. After completion of the intervention, the participants again were asked to take the posttests of physical fitness and competency.

Participants. In the current semiexperimental study, the statistical population included all 2nd grade students of Sama junior School in Boroujerd, Iran. Among the statistical population, the researchers selected two 18member groups in a way that the first group received sport education and the 2 nd group the traditional method in volleyball. The participants were randomly selected. The sessions were held from February 2014 to May 2015 for 12 weeks. Each session lasted 90 minutes and the students were taught by two skilled physical education teachers in volleyball.

Data Collection Tool. In the current study, both the groups took pretests as the standard test of physical fitness and competency approved by Iran Department of Education.

Measurements. The descriptive statistics were used to analyze the data with SPSS version 19.

Conceptual Model. The model used in the current research had the following steps: The first step was to design the original research pattern. Then, the two independent variables of physical fitness and competency were measured by pre- and posttests. The conceptual model of the research is shown in Figure 1.

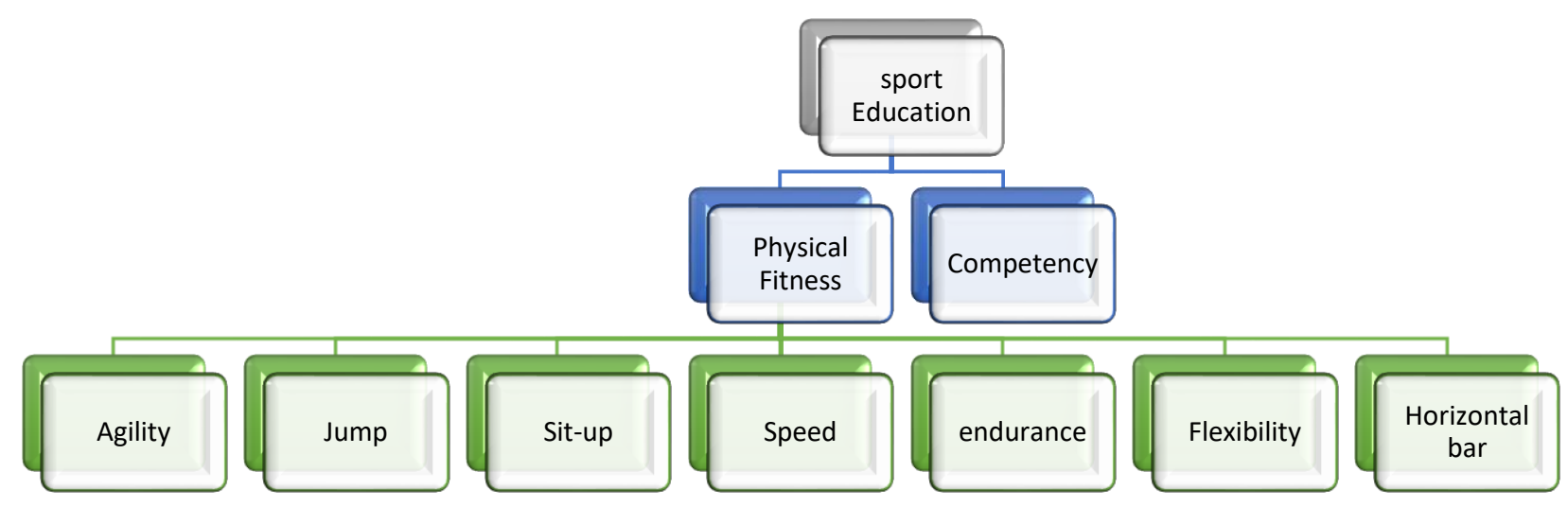

Figure 1. The Conceptual Model of the Research

\section{RESULTS}

The descriptive data including the height and weight of the participants is shown in Table 1.

According to the abovementioned measures, it can be concluded that both groups of sport education and traditional method were approximately similar in the studied variables. In addition, in order to find out the normality of the test, the researchers used the KolmogorovSmirnov test. After analyzing the data with the Kolmogrov-Smirnov test, according to $\mathrm{Z}$ value and the level of significancy, the normality of the test was approved, and therefore, the parametric statistics was used to analyze the data.
For the first independent variable, physical fitness, data analysis showed a significant difference between the effects of traditional and sport education methods on the physical fitness of the students. To analyze this result, the researcher used covariance and the results are shown in Table 2.

Table 1. Descriptive Data

\begin{tabular}{|lcc|}
\hline Variable & SE & TM \\
$\begin{array}{l}\text { Height } \\
(\mathbf{c m})\end{array}$ & $166.4 \pm 10.2$ & $167.8 \pm 6.9$ \\
$\begin{array}{l}\text { Weight } \\
\text { (kg) }\end{array}$ & $53.4 \pm 11.7$ & $57.6 \pm 10.1$ \\
\hline
\end{tabular}


Table 2. The Effect of Traditional and Sport Education Methods on Physical Fitness in the Studied Groups

\begin{tabular}{|c|c|c|c|c|c|c|c|}
\hline & Mean \pm Stand & rd Deviation & Adjusted Mean & Mean Square & $F_{(1,33)}$ & $\mathbf{P}$ & Eta Coefficient \\
\hline Agility & Pretest & Posttest & & 0.855 & $* 25.94$ & 0.001 & 0.43 \\
\hline Sport education & $0.91 \pm 10.87$ & $0.63 \pm 10.26$ & 10.26 & & & & \\
\hline Traditional method & $0.84_{ \pm} 10.78$ & $0.78_{ \pm} 10.5$ & 10.50 & & & & \\
\hline Jump & & & & 9.38 & 2.97 & 0.094 & 0.083 \\
\hline Sport education & $11.4 \pm 32.9$ & $10.8_{ \pm} 37.9$ & 37.94 & & & & \\
\hline Traditional method & $9.8_{ \pm} 32.67$ & $9.1 \pm 36.67$ & 36.67 & & & & \\
\hline Sit-up & & & & 31.81 & *19.42 & 0.001 & 0.37 \\
\hline Sport education & $0.10 .9 \pm 30.56$ & $9.1 \pm 35.28$ & 35.27 & & & & \\
\hline Traditional method & $9.9 \pm 31.06$ & $9.3 \pm 33.8$ & 33.83 & & & & \\
\hline Speed & & & & 0.286 & *21.97 & 0.001 & 0.40 \\
\hline Sport education & $0.35 \pm 7.52$ & $0.34 \pm 7.12$ & 7.12 & & & & \\
\hline Traditional method & $0.36 \pm 7.51$ & $32 \pm 7.29$ & 7.29 & & & & \\
\hline Endurance & & & & 1.06 & *18.34 & 0.001 & 0.36 \\
\hline Sport education & $0.56 \pm 8.89$ & $0.49 \pm 8.4$ & 8.40 & & & & \\
\hline Traditional method & $0.51 \pm 8.9$ & $0.53 \pm 8.76$ & 8.76 & & & & \\
\hline Flexibility & & & & 32.06 & $* 41.05$ & 0.001 & 0.55 \\
\hline Sport education & $4.1_{ \pm} 38.17$ & $3.4_{ \pm} 42.17$ & 42.17 & & & & \\
\hline Traditional method & $3.03 \pm 38.5$ & $3.01 \pm 40.6$ & 40.61 & & & & \\
\hline Horizontal bar & & & & 23.52 & $* 5.19$ & 0.030 & 0.135 \\
\hline Sport education & $4.9 \pm 34.72$ & $5.1 \pm 38.39$ & 38.39 & & & & \\
\hline Traditional method & $4.89 \pm 33.94$ & $5.5 \pm 36$ & 36 & & & & \\
\hline
\end{tabular}

According to the information in Table 2, the results of the covariance test showed that by eliminating the effect of pretest as an overlapping variable, the main effect of differences between sport education and traditional methods on agility, sit-up, speed, endurance, and flexibility was significant, and in all of them, the significance was in the interest of sport education method. In the case of jump variables, according to the statistical data presented in Table 2, both educational methods may increase the amount of this variable, but did not differ significantly in the amount of this increase. Therefore, by comparing the effects of traditional and sport education methods on the physical fitness of the students, it was concluded that sport education method was much better and more effective on the physical fitness of the students rather than traditional method.

For the 2nd independent variable of competency, data analysis showed that there is a significant difference between the effects of traditional and sport education methods on the competency of the students. Again, in order to analyze this claim, the researcher used covariance and the results are shown in Table 3.

Table 3. The Effect of Traditional and Sport Education Methods on Competency

\begin{tabular}{|lccccccc|}
\hline Competency & \multicolumn{2}{c}{$\begin{array}{c}\text { Mean } \pm \text { Standard } \\
\text { Deviation }\end{array}$} & $\begin{array}{c}\text { Adjusted } \\
\text { Mean }\end{array}$ & $\begin{array}{c}\text { Square } \\
\text { Mean }\end{array}$ & F (1,33) & P & Eta Coefficient \\
Sport education & $11.2 \pm 34.61$ & $8.6 \pm 55.33$ & 55.33 & 1597.35 & $* 45.79$ & 0.001 & 0.58 \\
Traditional method & $11.3 \pm 35.83$ & $11.4 \pm 42.89$ & 42.89 & 1597.35 & $* 45.79$ & 0.001 & 0.58 \\
\hline
\end{tabular}

According to data shown on Table 3 for sport education, the results of ANCOVA showed that by eliminating the effect of pre-test as an overlapping variable, there was a significant difference between the main effects of sport education and traditional methods on competency in favor of sport education method. Therefore, by comparing the effects of traditional and sport education methods on the competence of the students, it can be concluded that sport education is much better and more effective than traditional method on the competence of students.

\section{DISCUSSION}

The current study aimed at comparing the effects of traditional and sport education methods on physical fitness and competency of 2 nd grade Sama junior School students in Boroujerd, Iran. The current semi-experimental study was conducted on the effects of two aforementioned 
methods. The statistical population consisted of all 2nd grade Sama junior School students in Boroujerd, of which the researchers selected two 18-member groups in a way that the first group was trained based on the sport education method and the 2nd group based on the traditional method in volleyball. Each group attended the sessions held based on the running method. For the sport education group, before starting the intervention, the participants were asked to take the pre-tests for physical fitness and competency. Likewise, subjects in the traditional group took pretests before starting the intervention. Then, the intervention was performed in each group based on the structure, procedure, and lesson plan of the running method. After completion of the intervention, the participants were again asked to take the post-tests of physical fitness and competency. The data from pre- and post-tests were gathered and compared using covariance with SPSS. Finally, the results indicated a significant difference between the two groups in physical fitness (except for jump), as well as a significant difference between the pretest and posttest results of each group in competency, and the sport education was superior to traditional method.

The present research also had some limitations as well as suggestions. In terms of limitations, it was first performed on the boy students of the 8th grade in Borujerd Sama Schools. Also, the number of participants in the study was 36, consisting of two 18-student classes. The third limitation was that the study was conducted within 12 weeks in the school. Other important limitations were genetic differences of the subjects, their motivation to attend the sessions, and also filling the questionnaire. Finally, some factors such as nutritional status, sleep time, and resting time of the subjects were the important limits, which could not be controlled by the researchers.

\section{CONCLUSION}

Considering the above mentioned issues, the present study suggests that instead of using common and traditional teaching methods for physical education in schools, colleges and universities, it is better to use modern methods, especially sports education; in other words, it is better to use sports education as an exercise method to increase the competence of students and enhance their physical fitness in physical education classes.

\section{APPLICABLE REMARKS}

The results of the research can help sports managers of free zones to:

- Provide students with a more authentic and enjoyable sport experience in physical education.

- Increase the skills of physical fitness, competency, literacy, and enthusiasm among students

- Organize the students into mixed-ability teams to stay together throughout the season.

- Turn the level of sport curriculum from a traditional and simple one into a standard and new which is similar to professional sport.

- Teach students to be responsible and regular in sport classes.

- Teach students to be cooperative.

\section{REFERENCES}

1. Siedentop D. Sport Education: Quality P.E. through positive sport experiences. 2nd ed. Champaign, IL: Human Kinetics; 2011.

2. Mooney A, Moncrieff K, Hickey C. Exploring pre-service teachers' experience of Sport Education as an approach to transition pedagogy. Phys Educ Sport Pedag. 2018;23(6):545-558. doi: 10.1080/17408989.2018.1485137

3. Wallhead T. Developing effective student coaches in Sport Education. Act Health J. 2017;24(2):3.

4. Wallhead T. Sport Education: A model for Engaging Teachers and Students. Act Health J. 2018;25(3):4.

5. Wallhead T, Hastie P. Designing a Sport Education season: Key factors to consider. Act Health J. 2018;25(3):4.

6. Flinders P, Williams J. Pursuing physical education outcomes through Sport Education. Canberra: University of Canberra; 2018.

7. Wallhead T. Developing effective student coaches in Sport Education. Act Health J. 2017;23(1):3.

8. Farias C. Promoting equity and social responsibility within Sport Education. UK: University of Bedfordshire; 2018. 
9. Layne T. Sport Education in the primary grades. USA: University of Memphis; 2018.

10.Farias C, Hastie PA, Mesquita I. Scaffolding student-coaches' instructional leadership toward student-centred peer interactions. Eur Phys Educ Rev. 2017;24(3):269-291. doi: $10.1177 / 1356336 \times 16687303$

11. Ratten V, Jones P. Future research directions for sport education: toward an entrepreneurial learning approach. Educ Train. 2018;60(5):490-499. doi: 10.1108/et-02-2018-0028

12.Ratten V, Jones P. Sport education: fit for a purpose. Educ Train. 2018;60(5):370-374. doi: 10.1108/et-06-2018-209

13.Farias C, Mesquita I, Hastie PA, O'Donovan T. Mediating Peer Teaching for Learning Games: An Action Research Intervention Across Three Consecutive Sport Education Seasons. Res $Q$ Exerc Sport. 2018;89(1):91-102. doi: 10.1080/02701367.2017.1402114 pmid: 29220620

14. Alexander K, Luckman J. Australian Teachers\&iacute; Perceptions and Uses of the Sport Education Curriculum Model. Eur Phys Educ Rev. 2016;7(3):243-267. doi: 10.1177/1356336x010073002

15. Ames C. Achievement goals and the classroom climate. In: Roberts C, editor. Motivation in sport and exercise. Champaign, IL: Human Kinetics; 1992. p. 161-176.

16. Gaini A, Rajabi H. [Physical Fitness Book]: Samt Publishing Press; 2003.

17.Doll-Tepper G. Sport, Education and Social Policy: The state of the social sciences of sport (ICSSPE Perspectives). 1st ed: Routledge; 2018.

18. Wallhead TL, Ntoumanis N. Effects of a Sport Education Intervention on Students' Motivational Responses in Physical Education. Journal of Teaching in Physical Education. 2004;23(1):4-18. doi: 10.1123/jtpe.23.1.4

19. Arefian NM, Zali AR, Seddighi AS, Fathi M, Teymourian H, Dabir S, et al. Clinical Analysis of EEG Parameters in Prediction of the Depth of Anesthesia in Different Stages: A Comparative Study. Tanaffos. 2009;8(2):46-53.

20. Teymourian H, Mohajerani SA, Bagheri P, Seddighi A, Seddighi AS, Razavian I. Effect of Ondansetron on Postoperative Shivering After Craniotomy. World Neurosurg. 2015;84(6):19231928. doi: 10.1016/j.wneu.2015.08.034 pmid: 26342782

21.Kiss M. Cambridge Checkpoints VCE Physical Education Units 3 and 42018 and Quiz Me More. Cambridge Cambridge University Press; 2018. 